\title{
Parental Involvement in Speech Activities of Speech Delayed Child at Home
}

\author{
Aliza Alias ${ }^{1 *}$, Umithayyibah Ramly ${ }^{2}$ \\ ${ }^{1}$ Faculty of Education, Universiti Kebangsaan Malaysia 43600 Bangi Selangor Malaysia \\ ${ }^{2}$ SMK Alor Akar, Jalan Tengku Muhamad, 25050, Kuantan, Pahang, Malaysia \\ *Corresponding author. Email: eliza@ukm.edu.my
}

\begin{abstract}
Speech activities in speech therapy are frequently applied of early interventions to children with speech delay. The speech therapy was conducted to assist the children with speech difficulties. However, these speech activities need to be implemented regularly at home as a reinforcement to the speech therapies attended at clinics. Therefore, this paper discusses the factors of parental involvement in implementing speech activities at home. In this study, two parents who each has a child with speech delay, were interviewed using semi-structured questions. Triangulation was utilized using two types of data collection technique: interview and document analysis. The interview transcripts and parents' personal notes throughout the speech therapy session with speech therapists were analyzed using The ATLAS.ti (version 4.1). Five factors were found on parental involvement in their children's speech activities at home: a) perceived language development, (b) emotion, (c) knowledge, (d) children's performance and (e) support. These factors motivate the parents to continue conducting speech activities relentlessly at home. Furthermore, the training and guidance from speech therapist on how to conduct speech activities successfully at home, would reinforce the children's speech development and eventually overcome the speech difficulties faced by the children.
\end{abstract}

Keywords: Speech Delay, Speech Activities, Parental Involvement, Speech Therapist

\section{INTRODUCTION}

Parents play an important role in nurturing their children's development since birth. Parental involvement in a child's learning has been identified as one of the factors that assist children's development. Researches have shown that parents play an important role in their children's language development $[1,2,3,4,5]$. Four aspects of language development involving parents-child interactions are the amount of interaction between parents and the child; the response to the child's communication; the amount and quality of linguistic input; and the use of learning strategies [4]. Parental involvements are important in children's development [6] such as asking about school homework and helping in completing the homework, participation in school activities or parents-teacher communication on the child's performance.

\subsection{Parental Involvement}

Parental involvement in speech therapy activities could shorten the amount of time allocated to the child's undergoing speech therapy session [7]. Speech therapy is one of the early interventions for children with delayed speech. For example, parental involvement in intervention and interaction has helped in reducing stuttering faced by preschool children after undergoing only six therapy sessions at clinics and six weeks of therapy by parents at home [2]. Speech activities at home play a role as reinforcement to the therapy session with the experts at the clinic. Parents were involved and informed of their role in implementing the early interventions activities [8]. Therefore, this study identified the factors that influent parents to be involved in speech activities at home. In a study by Gunther and Hautvast [7], parents' frequency in performing speech assignment given by the therapists, has been measured by parents' reports on the time and duration allocated to conduct the speech training with their children. Parents were trained to observe symptoms shown by the child during communication, to stimulate the child to communicate using structure conversation and to guide the child to communicate verbally and non-verbally. 
A meta-analytic study by Robert and Kaiser [5] reported that parental involvement in intervention program is very effective if they are trained to assist their children to overcome the problems of communication, language and speech. Interventions conducted by trained parents showed positive effects to children's language development. Various approaches have been used to conduct therapy involving parents such as parent-child interaction, parent interventions and training at home [9]. An approach used to reduce the children's speech problem by engaging parents directly is Parents-Child Interaction Therapy. Through parents' interaction approach, therapists would guide parents to increase the child's knowledge and understanding in communication [2]. The use of video recording helps the therapists in analyzing the parent-children interaction. The therapists identify how the parents help their children to communicate effectively, in addition to encourage communication that is of high quality, spontaneous and relevant to the situation using various techniques. If the quality of interaction between parents and children increases, opportunities for language learning to occur would also increase [10,11]. The intervention effect of parents who underwent training was positive and significant towards children language development [11]. As a result of involvement with training programs to conduct interventions, parents succeeded in mastering the strategies and used them when interacting with children. Parents believed they could make a change and improve their children's communication problem. Parents used the strategies learned to enhance their children's skill of expression including non-verbal and speech communication, comprehension, vocabulary, grammar and the frequency of children's speech. In addition, the children with multiple language problems showed a good progress when parents were trained to assist them. This included children with language delay, autism and developmental problem [4,5].

\section{METHOD}

This case-study was conducted by interviewing two parents who each has a child with speech delay. The participants were selected using purposive sampling. The ATLAS.ti (version 4.1) software was used to analyze the interview transcripts and parents' personal notes throughout the speech therapy session with speech therapist. The data from the interview were verbatim transcripted and analyzed based on themes identified from the implementation of speech activities at home. The interview questions were adapted from semistructured interview by Kummerer and Lopez-Reyna [12]. According to Chua [13], semi-structured interview allows the use of framework that facilitates the analysis of research data. It is a small-scale research that focuses on the parental involvement in speech activities at home only and the roles of parents in implementing speech activities at home. In addition to the interview, document analysis was done on the personal notes of the two parents during the speech activities. The two parents (P1 \& P2) who each has a child with speech delay aged 4 years old. Both boys had undergone speech therapy from 12 to 18 months.

The problems faced by these two boys were different as P1's son has speech delay and developmental level of a one year-old child even though the child has good focus. The boy couldn't imitate the lip movement, sound, words or physical movement and did not know how to actually play. Besides, the boy who started speech therapy at the age of 2 years and 9 months, often played alone resulting in lack of interaction and communication. Whereas, P2's son has autism and started speech therapy at the age of 2 years and 6 months. He always repeated other people's speech (echolalia) and did not speak much and did not want to socialize. The boy was also confused when differentiating small ' $b$ ' and small ' $d$ ' as well as the colors of red and orange.

\section{FINDINGS}

The findings of this study were discussed based on the themes identified from the analyses of interviews' transcription and personal notes of the parents which are perceived language development, emotion, knowledge, support and child's performance.

\subsection{Perceived Language Development}

Parents' perception towards children's language development is influenced by hearing ability, gender, genetic and age of the children. Parents perceived that the children's speech problem is due to genetic factors since there are family members who have speech delay. Besides, the parent were hopeful that the children would acquire the language and speak at certain level of age like other children of their age. It showed that the parents were aware of their children's language development. Below are the excerpts from the interview translated from Bahasa Malaysia to English Language.

“...but most children of similar age with my child are already speaking fluently.” (P1)

"My mother said that my siblings have speech delay problem. But my husband's family do not have such problem." (P2)

These parents were also concerned about their children's ear condition because they were aware that if the ears have problem, it would affect their children's speech ability. Having hearing problems would affect the child's ability to speak. Therefore, they took their children to see ENT (Ear, Nose \& Throat) specialist at the hospital to get treatment needed on the matters, to ensure it would not interfere the child's ability to speak and communicate. 


\subsection{Emotion}

Emotion plays and important aspect in motivating parents to get involved with their child's development. Both parents felt that their emotion in facing challenges were related to the language problem faced by their children. These parents' emotions motivated them to continue assisting their children with speech activities. They were also determined to take their children for speech therapy session at the clinic and continued practicing the speech activities together with their children at home. Below are excerpts from the interview translated from Malay language to English language.

“...when I am determined to continue with my child's therapy, it makes me stronger to face the problem." (P2)

Parents often felt sad and worried about their children's language development. They also felt guilty as the children's development and well-being were their responsibility as parents. Even when faced with difficulties, the parents were determined to face the problems together with patience. Positive improvement of their children language development made the parents happy and thankful that they sent their children for speech therapy, besides being happy with the outcomes of the speech activities conducted at home.

"Of course, I am sad and worried with my child's development." (P1)

"It's not your responsibility alone, it's a shared responsibility." (P2)

"Lots of changes... I like it." (P2)

The parents were seen to have their own expectation toward their children's achievements. They wished that their children were able to communicate with others, understand questions and able to answer questions appropriately, at least simple questions. Parents' expectations toward their children, gave them motivation to continue the speech activities until their children were able to speak at a satisfactory level.

"I hope he [her child] will be able to speak fluently so that he can communicate with others." (P1)

"If my child can speak, understand every question and answer and have a conversation with me that would be good enough for me." (P2)

Analysis of the parents' notes support the findings from the interviews where the parents felt afraid, anxious and worried if their children would be lagging behind compared to their peers. The parents strived to assist their children so that they would be able to communicate in their daily life as the peers do.

"I feel threatened. I feel worried if my child is lagging behind from his peers. But I will remain strong." (P1)

\subsection{Knowledge}

Parents have the experience in assisting children implementing speech activities at home. They played a role in ensuring their children to undergo speech activities at home and allocating time for their children, preparing their children's time-tables and giving reinforcements as part of motivation for the children to stay committed to the speech activities at home. Parents believed that the time spent with children during the speech activities, even for a short period of time, would impact their children's speech development.

"Setting up time-table for my children..." (P2)

Reinforcements for the speech activities were in a form of token economy and rewards desired by the children. In addition, praises were given to motivate the children towards performing speech activities. Parents' observation on the children undergoing therapy session at the clinic where the therapists often give reinforcement to encourage the children to speak. These helping hand from the therapists has guided the parents to implement the same strategy during speech activities at home.

"I said... if you want ice-cream, you have to complete the tasks.” (P2)

“The doctor gave heaps of praises to my child." (P2)

Knowledge about early intervention influenced the parents to send their children to the speech therapists after detecting speech problems.

"I am worried if we delay the [speech] therapy, the problem will be escalated." (P1)

Knowledge obtained from therapists, guidance, selfreading, internet searches and attending speech therapy workshop organized by speech therapist increased the parents' confidence in implementing speech activities at home. Parents became more sensitive toward their children's needs and understand the objectives of the speech activities they did at home.

"Through this workshop, I understand why certain activities are performed during the speech therapy session. I also do a lot of internet searching for suitable activities that can be done at home." (P1)

Based on parents' personal notes, it was also found that the therapists guided the parents to prepare conducive environment for their children to conduct the speech activities at home.

[The therapist said]: "Here [at the therapy session], your child can focus. At home, the environment is different... here your child saw that the parents give attention to him... that's what he wants [at home]." (P2) 


\subsection{Support}

A part from the therapist's support during therapy sessions at the clinic, the parents also received support from their spouses and family members at home. It made them feel that their involvement was important and they were motivated to conduct the speech activities at home. The parents also acknowledged that the speech activities done with their children as a learning process for them in helping their children to acquire better communication skills.

\section{“My husband helps a lot.” (P1) \\ "...at least 15 minutes (of speech activities at home) is enough... learn and grow together.” (P2)}

The therapists' client-friendly style during therapy session helped parents in understanding the therapists' explanation on how to conduct speech activities needed at home.

“...very friendly... make me understand his explanation better. "(P2)

A good support system from family members and speech therapist, give parents strength to continue assisting their child's in speech activities at home.

\subsection{Children's Performance}

After undergoing speech therapy session at the clinic and speech activities at home, there were positive changes in the children's speech development. These positive outcomes has an impact on the parents' motivation and emotions. Their sons who were only able to utter a few words at the beginning of the speech therapy program, showed impressive improvement in answering simple questions posed to them.

"Before this I seldom had conversation with my child... but now I do." (P1)

"My child has improved a lot in his speech... so many words came out from his mouth." (P1)

"now no more mumbling." (P2)

Speech activities at home improved the selfconfidence of the children with speech problems. Parents were informed by the school teachers that their children also have improved their speech in school and interacting with their classmates in class.

“... My child now has self-confidence... teachers also noticed his improved speech due to speech activities at home." (P2)

\section{DISCUSSION}

The research findings revealed that five factors compel the parents to be involved in speech activities at home: parents' perception towards their children language development, parents' emotion towards their children's problem, parents' knowledge on the importance of speech training at home and changes shown by their children after undergoing speech therapy as well as supportive spouses, family and speech therapists. These factors motivate the parents to continue implementing speech activities at home for the children's benefits. These activities are considered as interventions on the children's language development. Even though, the parents did not necessarily know the techniques and instructional methods in conducting these activities, but they bravely did it based on what they had learnt from the therapists [8]. Parents who have children with speech delay often concern about the future of their children. They hope that their children would be able to communicate better in their daily life like their peers in the society. Parents would definitely feel relieved and satisfied even though their children showed little improvement in their speech ability.

Parents felt that the effort and time spent on the speech activities at home are worthwhile. Hornby and Lafaele [14] stated that changes in family structure that increase parents' time spent at work and mobility, addition of new family members or dual-career parents, divorce cases or marriage that causes competition between siblings are factors that increase parents' stress, decrease family income, and decrease time, which lead to difficulty for optimum involvement with children's education. Grindle et al. [15] found that almost half of parents who were involved in home intervention program for children with autism reported that their involvement had reduced their own stress. Their stress level decreased when they noticed their children's improvement. Parents who were involved in their children's therapy also reported improved relationship with their children due to the children's improved communication after undergoing therapy. Parents' perception towards children's language development increased their awareness [16] on their children's speech delay, thus compelling them to seek professional services for help.

Lewis et al. [17] compared between parents with history of speech problem with those without such history by measuring the outcomes of speech sound, phonology process, language, readings and spellings. The study found that parents with speech problems during their childhood scored lower in assignments related to words repetition, but not related to words and tongue twister. The parents also showed weaknesses in readings, spellings and receptive language skill. Hence, it can be assumed that the probability that other family members are having speech problem is higher compared to parents without any history of speech problem. Quittner et al. [18] studied the relationship between delay in mastery of language, children behavioral problem and parental stress. The research found that children with delay in language mastery demonstrated problems in regulating emotion, attention and behaviors. These children are facing difficulty in expressing their needs, leading to frustration and undesirable behaviors. Not only 
that, the children also face difficulties in communication and understanding their parents' instructions.

The knowledge that the parents acquired from the speech workshop, sharing session with the therapists, observing during therapy session at the clinics, reading and searching information from the internet had increased the parents' confidence to conduct the speech activities at home [19]. Therefore, the parent could conduct a variety of speech activities not only during the time allocated, but also during various daily activities. The session with therapists also gave the opportunity and guidance to parents in conducting the activities in the interest of their children's development [8]. The skills that the parents learned from the therapists such as observing their children would provide information on how to identify the children's difficulties in communicating. On top of that, the collaboration between parent and therapists would enhance the effort to encourage the children's skill in communication and speaking [10].

The use of multiple activities is an interesting approach to attract the children to do speech activities with their parents at home so they would not feel bored and uninterested [11]. In addition to that, applying the concept of play in speech activities could maintain the momentum of fun learning process for the children and reduce the pressure they are facing during the activities. Fun activities also encouraged the child to interact and communicate actively with their parents [9]. The speech activities that were chosen by parents should be creative and fun in order to initiate the children participation in activities.

The usage of reinforcements and token economy could motivate the children with speech delay to participate in the speech activities at home and show interest in participating in the activities. These techniques can encourage the children to engage in the activities and become the indicators of the parents' success in managing the children [2]. The spouses' role of encouraging their partners to engage actively poses positive effects to the children's speech development. Spouses' supports are usually inconsistent, but still relevant to the children's best interest $[11,20]$.

\section{CONCLUSION}

This study has highlighted the factors that influence parental involvement in conducting speech activities at home with their children. Furthermore, the therapists' supports and suggestion on appropriate strategies and activities that need to be conducted at home by the parents, increased the parents' confidence to get involve in the speech activities at home. The appropriate speech activities conducted at home by parents should be able to provide variety of choices as sources of references for other parents who are interested to conduct speech activities on their own at home. As a conclusion, parental involvement is important in assisting the development of their children in overcome their speech difficulties. The parents in this study showed a lot of relentlessly efforts in conducting the speech activities at home as long as the children could improve their speech and communication in their daily life. Speech workshop and training for parents should be offered to ensure that they are equipped with necessary knowledge and skills that enable them to contribute positively to the development of their children's speech.

\section{ACKNOWLEDGMENTS}

This work was supported by a research from Faculty of Education, Universiti Kebangsaan Malaysia. (FPEND GG-2019-029).

\section{REFERENCES}

[1] I. Cruz, A. L. Quittner, C. Marker, J. L. Desjardin, Identification of effective strategies to promote language in deaf children with cochlear implants, in Child Development, 84(2), 2013, pp. 543-559. DOI: https://doi.org/10.1111/j.1467-8624.2012.01863.x

[2] S. K. Millard, A. Nicholas, F. M. Cook, Is parentchild interaction therapy effective in reducing stuttering?, in Journal of Speech, Language, and Hearing Research, 51(3), 2008, pp. 636-650. DOI: https://doi.org/10.1044/1092-4388(2008/046)

[3] L. Pennington, K. Thomson, P. James, L. Martin, R. McNally, Effects of it takes two to talk-The Hanen program for parents of preschool children with cerebral palsy: Findings from an exploratory study, in Journal of Speech, Language, and Hearing Research, 52(5), 2009, pp. 1121-1138. DOI: https://doi.org/10.1044/1092-4388(2009/07-0187)

[4] M. Y. Roberts, A. P. Kaiser, The effectiveness of parent-implemented language interventions: A meta-analysis, in American Journal of SpeechLanguage Pathology, 20, 2011, pp. 180-199. DOI: https://doi.org/10.1044/1058-0360(2011/10-0055)

[5] M. Y. Roberts, A. P. Kaiser, Assessing the effects of a parent-implemented language intervention for children with language impairments using empirical, in Journal of Speech, Language and Hearing Research, 55, 2012, pp. 1655-1671. DOI: https://doi.org/10.1044/1092-4388(2012/11-0236)

[6] V. B. Bartel, Home and school factors impacting parental involvement in elementary school, in Journal of Research in Childhood Education, 24(3), 2010, pp. 209-228. DOI: https://doi.org/10.1080/02568543.2010.487401 
[7] T. Gunther, S. Hautvast, Addition of contingency management to increase home practice in young children with a speech sound disorder, in International Journal of Language \& Communication Disorders, 45(3), 2010, pp. 345353. DOI: https://doi.org/10.3109/13682820903026762

[8] L. Ping Yee, M. Mohd Ali, Amalan program intervensi awal kanak-kanak autistik mengikut perspektif ibu bapa, in Jurnal Pendidikan, 33, 2008,pp. 19-33.

[9] S. Asid, A. Alias, Jigsaw puzzle dalam meningkatkan kemahiran sosial dan komunikasi bagi murid pemulihan khas: Satu kajian kes, in International Conference on Learning Innovation and Quality Education $1^{\text {st }}$ Series Proceeding, 2016, pp. 816-824

[10] J. Allen, C. R. Marshall, Parent-child interaction therapy in school-aged children with SLI, in International Journal of Language and Communication Disorders, 46, 2011, pp. 397-410.

[11] S. Hashim, C. C. Tee, R. Abdul Majid, Z. Mohd Jelas \& H. A. Md Yusof, Perkembangan Kecerdasan Emosi Kanak-Kanak Prasekolah Bermasalah Pendengar: Implikasi Terhadap Penglibatan Ibu Bapa, in Akademika, 82(2), 2012, pp. 137-142.

[12] S. E. Kummerer, N. A. Lopez-Reyna, The role of Mexican immigrant mothers' beliefs on parental involvement in speech-language therapy, in Communication Disorders Quarterly, 27(2), 2006, pp. 83-94. DOI: https://doi.org/10.1177/15257401060270020601

[13] Y. P. Chua, Kaedah dan statistik penyelidikan: Kaedah penyelidikan, McGraw-Hill Education: Shah Alam, 2011.

[14] G. Hornby, R. Lafaele, Barriers to parental involvement in education: An explanatory model, in Educational Review, 63(1), 2011, pp. 37-52. DOI: https://doi.org/10.1080/00131911.2010.488049

[15] C. F. Grindle, H. Kovshoff, R. P. Hastings, B. Remington, Parents' experiences of home-based applied behavior analysis programs for young children with autism, in Journal of Autism and Developmental Disorder, 39(1), 2009, pp. 42-56.

[16]M. Ahmad Marzuki, S. Rahman, Parental involvement: A strategy that influences a child's health related behavior, in Health Science Journal, 10, 2015, pp. 1-7.

[17] B. A. Lewis, L. A. Freebairn, A. J. Hansen, L. Miscimarra, S. K. Iyengar, H. G. Taylor, Speech and language skills of parents of children with speech sound disorder, in American Journal of SpeechLanguage Pathology, 16(2), 2007, pp. 108-118. DOI: https://doi.org/10.1044/1058.0360

[18] A. L. Quittner, D. H. Barker, I. Cruz, C. Snell, M. E. Grimley, M. Botteri, CDaCI Investigation Team, Parenting stress among parents of deaf and hearing children: Association with language delays and behavior problems, in Science and Practice, 10(2), 2010, pp. 136-155.

[19] S. H. Ramly, A. Alias, Aspek kekeluargaan Model Epstein mempengaruhi tahap penglibatan ibu bapa dalam pelaksanaan rancangan pendidikan individu murid berkeperluan khas, in Proceeding of $2^{\text {nd }}$ International Conference Special Education on Special Education, 2017,pp.136-145.

[20] R. F. Narr, M. Kemmery, The nature of parents support provided by parents' mentors for families with deaf/hard-of-hearing children: Voices from the Start, in The Journal of Deaf Studies and Deaf Education, 20(1), 2014, pp. 67-74. DOI: https://doi.org/10.1093/deafed/enu029 